\title{
Low-Temperature Sintering Bonding Using Silver Nanoparticle Paste for Electronics Packaging
}

\author{
Wei Guo, ${ }^{1}$ Zhi Zeng, ${ }^{2}$ Xiaoying Zhang, ${ }^{1}$ Peng Peng, ${ }^{3}$ and Shanping Tang ${ }^{1}$ \\ ${ }^{1}$ School of Mechanical Engineering and Automation, Beihang University, Beijing 100191, China \\ ${ }^{2}$ School of Mechanical, Electronic, and Industrial Engineering, University of Electronic Science and Technology of China, \\ Chengdu 611731, China \\ ${ }^{3}$ Mechanical and Mechatronics Engineering, University of Waterloo, Waterloo, ON, Canada N2L 3G1
}

Correspondence should be addressed to Zhi Zeng; zhizeng@uestc.edu.cn

Received 22 January 2015; Revised 12 May 2015; Accepted 18 May 2015

Academic Editor: Changhong Ke

Copyright (C) 2015 Wei Guo et al. This is an open access article distributed under the Creative Commons Attribution License, which permits unrestricted use, distribution, and reproduction in any medium, provided the original work is properly cited.

Ag nanoparticles (NPs) with about $40 \mathrm{~nm}$ diameter covered with $5-8 \mathrm{~nm}$ organic shell were prepared by chemical reduction reaction. The thermal characteristics of Ag nanoparticle (NP) paste were measured by thermogravimetric analysis (TGA) and differential scanning calorimetry (DSC). The low-temperature sintering bonding processes using Ag NP paste were carried out at the temperature range of $150-350^{\circ} \mathrm{C}$ for $5 \mathrm{~min}$ under the pressure of $3 \mathrm{MPa}$. The microstructures of the sintered joint and the fracture morphology were evaluated by scanning electron microscopy (SEM). The shear strength was used to evaluate the mechanical property of the sintered joint. TGA-DSC test showed that the Ag content is approximately 95.5 mass\% in Ag NP paste. The average shear strength of the joint fabricated at $250^{\circ} \mathrm{C}$ for $5 \mathrm{~min}$ under the pressure of $3 \mathrm{MPa}$ was about $28 \mathrm{MPa}$, which could meet the requirements of electronics packaging working at high temperature. The joint shear strength increased with the increase of the sintering temperature due to much denser sintered Ag NPs and more comprehensive metallurgical bonds formed in the joint.

\section{Introduction}

Microelectronic devices and large power devices interconnection to the substrate is essential for device packaging, which provides paths for increased high power density electrical interconnection and high-efficiency heat dissipation [1]. However, the traditional eutectic or near eutectic $\mathrm{Sn}-\mathrm{Pb}$, $\mathrm{Sn}-\mathrm{Ag}$, and $\mathrm{Sn}-\mathrm{Ag}-\mathrm{Cu}$ solders and conductive adhesive used in die attachment are not reliable for high power density and high temperature electronic applications [2-4]. The $\mathrm{Pb}$-containing solder alloys $(\mathrm{Sn}-\mathrm{Pb})$ have been temporarily exempted from the Restriction of Hazardous Substances (RoHS) directive in the European Union due to serious health threat to human being and heavy pollution to environment $[5,6]$. On the other hand, it is reported that the joint using $\mathrm{Pb}$-containing solder and $\mathrm{Pb}$-free eutectic or near eutectic $\mathrm{Sn}-\mathrm{Ag}$ and $\mathrm{Sn}-\mathrm{Ag}-\mathrm{Cu}$ solders is not suitable for long-term usage at elevated temperature due to crack formation at the intermetallic (IMC) layer between the solder and the metallized substrate on the devices [7-9]. Thus, the new lead-free interconnection materials as alternative for device packaging have attracted much attention.

When material size is reduced down to nanoscale, some special characteristics, such as lower melting point [10], much higher surface energy [11], and diffusion coefficient [12], are significantly different from their parent materials in bulk. Therefore, a new low-temperature $\mathrm{Pb}$-free interconnection method is developed using the sintering of nanomaterial, in particular, nanoparticles (NPs) [13-18]. Among those NPs, silver (Ag) has been demonstrated as a candidate because of its excellent properties, such as high electrical conductivity, high thermal conductivity, and excellent high temperature service performance [15]. At present, low-temperature sintering of Ag NPs has been developed for bonding of semiconductor devices onto metalized substrate [16-21]. Unlike traditional liquid solder wetting, solid-liquid interfacial reaction, and solidification process, Ag NPs sintering bonding process is achieved under quite low temperatures, usually at $150-350^{\circ} \mathrm{C}$, through atomic diffusion and NP consolidation. 
Organic compounds are usually used to disperse and stabilize Ag NPs, which will be adsorbed on the surface of Ag NPs. During the sintering process, the removal of organic shell is a requisite by heating and thus being certain of the temperature is needed. After sintering process, the joint shows high melting point of pure $\mathrm{Ag}$ (about $960^{\circ} \mathrm{C}$ ) and excellent electrical and thermal properties as that of bulk Ag. Thereby, these sintered Ag NP joints produced at relatively low temperatures (below $350^{\circ} \mathrm{C}$ ) could be used at elevated temperatures (beyond $350^{\circ} \mathrm{C}$ ) at which the conventional solder joints could fail. Furthermore, this promising lowtemperature Ag NPs sintering process has wide potential applications in flexible electronics, including rapid prototyping [22], flat-panel printing [23], organic electronics [24], and low-cost disposable microelectronic devices on plastic substrates applications [25]. However, the microstructure evolution of the sintered joint during the sintering process is less studied. On the other hand, usually, the Ag NPs application is restricted by the long sintering times as it requires about 20-30 $\mathrm{min}$ [26].

In this paper, Ag NP paste was fabricated by chemical reduction method. The morphology and size distribution of Ag NPs have been observed by scanning electron microscopy (SEM) and transmission electron microscopy (TEM). Thermogravimetric analysis (TGA) and differential scanning calorimetry (DSC) were used to evaluate thermal characteristics of Ag NP paste. The rapid sintering experiment was performed in the furnace at air atmosphere. The mechanical property of the joint was evaluated using shear strength. The microstructure evolutions of the joint and the fracture surface morphology were also observed by SEM.

\section{Materials and Methods}

Ag NPs used in the experiment were prepared by modified reducing silver nitrate $\left(\mathrm{AgNO}_{3}\right)$ with ethylene glycol in the presence of polyvinylpyrrolidone (PVP) [27]. All of the chemical reagents were of analytical grade. First, $20 \mathrm{~mL}$ ethylene glycol solution of $0.3 \mathrm{M} \mathrm{AgNO}_{3}$ and $40 \mathrm{~mL}$ solution of PVP (0.9 M, K30) were prepared, respectively. The ethylene glycol solution was then heated to the reaction temperature of $160^{\circ} \mathrm{C}$. The PVP solution was injected into the silver nitrite solution at a constant rate of $0.3 \mathrm{~mL} \mathrm{~s}^{-1}$. When the solution color changed from colorless to gray (indicating the chemical reaction is completed), the solution was cooled rapidly through adding deionized water into the hot solution. Then, the Ag NP paste was collected by condensing the solution in a centrifuge (TW16-WS) with $7000 \mathrm{rpm}$ for $30 \mathrm{~min}$.

TGA and DSC analyses (STA 449 F3) were performed in air with the increase rate of $10.00 \mathrm{~K} \mathrm{~min}^{-1}$ to determine the organic content and the thermal properties of Ag NP paste. The morphology of Ag NPs and their size distribution were observed by SEM (JEOL 1530) and TEM (JEM-2100).

The nickel $(\mathrm{Ni})$ and $\mathrm{Ag}$ layers plated Copper $(\mathrm{Cu})$ discs were adopted as the electronics packaging connection samples in this work. The upper and bottom sizes of $\mathrm{Cu}$ discs were $\Phi 6 \mathrm{~mm} \times 5 \mathrm{~mm}$ and $\Phi 10 \mathrm{~mm} \times 5 \mathrm{~mm}$, respectively. Prior to bonding, the as-received $\mathrm{Cu}$ discs were ultrasonically

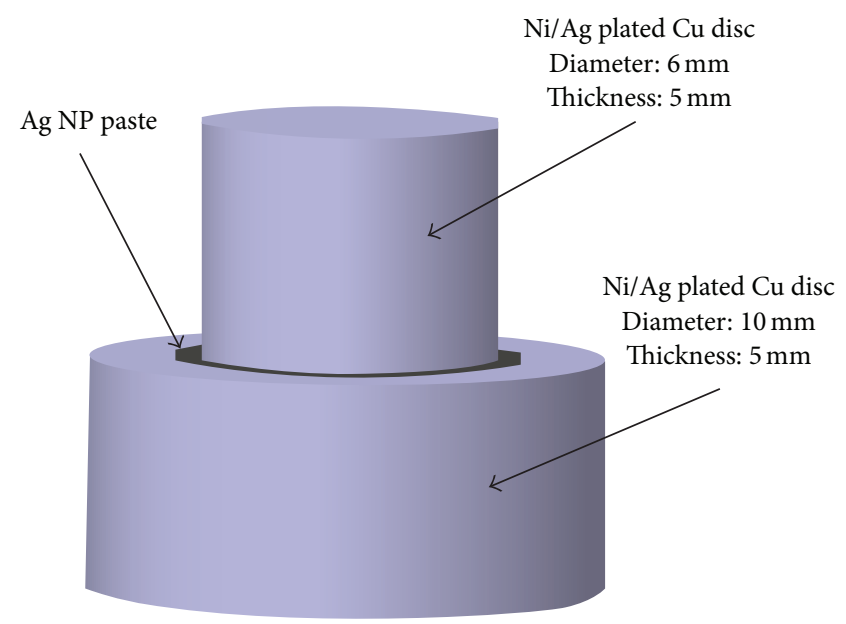

FIGURE 1: Schematic illustration of the sintering joint using Ag NP paste.

cleaned in acetone for $20 \mathrm{~min}$ to remove containments on the joining surface. Ag NP paste was blushed about $200 \mu \mathrm{m}$ on the surface of $\mathrm{Cu}$ discs and dried at $70^{\circ} \mathrm{C}$ on the heating plate for $10 \mathrm{~min}$. And Ag NP paste was sandwiched between upper and bottom $\mathrm{Cu}$ discs (shown in Figure 1). The sintering experiments were performed in the muffle furnace in air atmosphere from 150 to $350^{\circ} \mathrm{C}$ for 5 min under the pressure of $3 \mathrm{MPa}$. In detail, the furnace was heated to sintering temperature, holding for about $20 \mathrm{~min}$ for uniform temperature, and then the joining assembly was put into the furnace and put the pressure on the assembly. After sintering process, the assembly was taken out from the furnace.

The shear strengths of the sintered joints were evaluated using a Gleeble thermomechanical simulator (1500 D) with a displacement speed of $5 \mathrm{~mm} \mathrm{~min}^{-1}$ at room temperature. The interfacial microstructures of the joints and fracture surfaces were examined by SEM (CS3400 and JEOL 1530).

\section{Results and Discussion}

3.1. Morphologies of Ag NPs. Figure 2(a) shows the typical morphology of as-prepared Ag NPs. It can be seen that most of Ag NPs are polyhedron in shape. The distribution of Ag NP size was in the range of 20-80 $\mathrm{nm}$ (shown in Figure 3) and the average diameter of Ag NPs was about $40 \mathrm{~nm}$. Transmission electron microscopy (TEM) image of Ag NPs is displayed in Figure 2(b). An organic shell with a thickness of 5-8 nm is observed on the surface of Ag NPs, which prevented the oxidation and aggregation of Ag NPs.

3.2. Thermal Characteristics of Ag NP Paste. Figure 4 shows the TGA and DSC results of Ag NP paste. Two exothermic peaks in DSC curve are recognized at around 350 and $400^{\circ} \mathrm{C}$, respectively. When the temperature is above approximately $150^{\circ} \mathrm{C}$, some organic compositions covered on Ag NP may start to vaporize, oxidize, or burn out by reacting with oxygen in air or being adsorbed on $\mathrm{Cu}$ disc surface [28]. As known, nanoparticles tend to aggregate because of much 


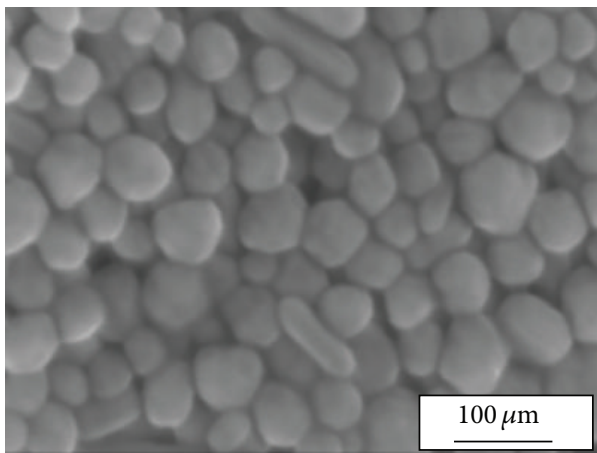

(a)

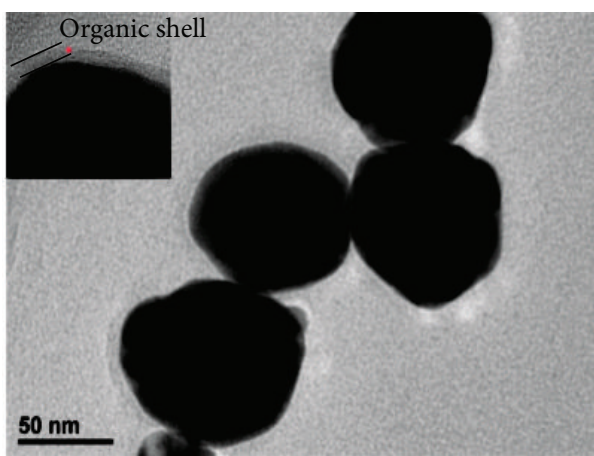

(b)

Figure 2: SEM (a) and TEM (b) images of Ag NPs.

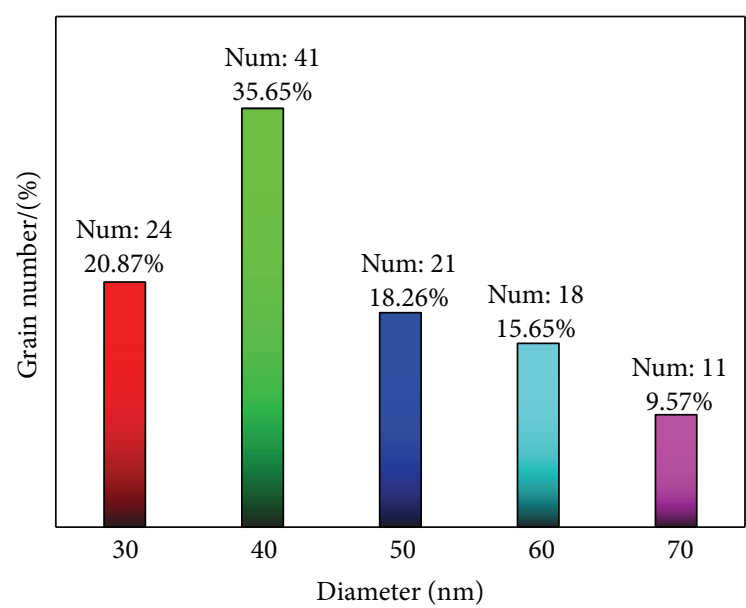

FIgURE 3: Ag NP size distribution.

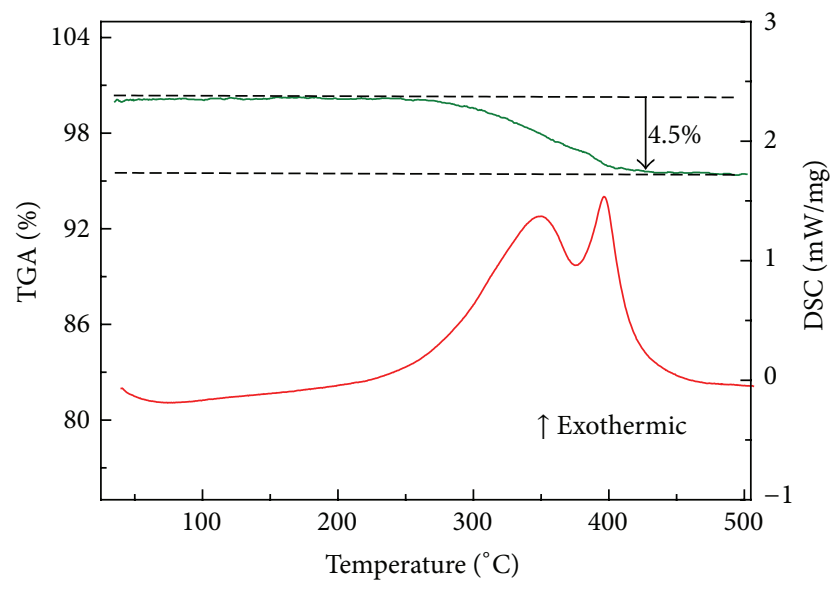

Figure 4: TGA and DSC curves of Ag NP paste.

higher surface energy $[18,29]$. The exothermic peak at around $350^{\circ} \mathrm{C}$ is mainly due to the decomposition of organic shell. The exothermic peak at $\sim 400^{\circ} \mathrm{C}$ is possibly attributed to the oxidation of C derived from PVP [30]. As shown in TGA curve, the weight of the dried paste gradually decreases as the temperature increases from room temperature to $450^{\circ} \mathrm{C}$, which can be attributed to vaporization and decomposition of the organic compounds in the paste. The Ag content of Ag NP paste was approximately 95.5 mass\%, which is significantly higher than 85 mass $\%$ in conventional Ag NP paste [13]. Since the bonding process is atom diffusion and sintering of $\mathrm{Ag}$ NPs with the vaporization and decomposition of the organic components. When the organic component reduces, Ag NPs aggregate and sinter together under the annealing temperature and pressure. Because of the much lower organic content of the Ag NP paste used in this research, it is reasonable to predict that it will have lower sintering temperature and shorter sintering time during bonding compared with the conventional Ag NP paste.

3.3. Microstructures of the Sintered Joint. Figures 5(a)-5(c) give the low magnification microstructures of the joint at the temperature of $150^{\circ} \mathrm{C}, 250^{\circ} \mathrm{C}$, and $350^{\circ} \mathrm{C}$, respectively. Macrocracks were observed between $\mathrm{Ag}$ coated layer and $\mathrm{Ag}$ NP sintered zone of the joint at $150^{\circ} \mathrm{C}$ as arrows indicated in Figure 5(a). Since only few organics vaporized and oxidized at the temperature of $150^{\circ} \mathrm{C}$ as shown in DSC curve in Figure 4, these cracks format the interlayer between $\mathrm{Ag}$ coated substrate and Ag NP sintered zone due to the residual organics in Ag NP paste. No significant macrocracks could be observed when the sintering temperature increased to $250^{\circ} \mathrm{C}$ and $350^{\circ} \mathrm{C}$ (see Figures 5(b)-5(c)), indicating that the joint strength would be increased. Meanwhile, a high magnification image of the connection areas of the joint is given in Figures 5(d)$5(\mathrm{f})$. It was found that the sintered zone of the joint at $150^{\circ} \mathrm{C}$ (Figure 5(d)) was composed of small size Ag NPs (several hundred nanometer diameter) with high percentage of pores. With the temperature increasing to $250^{\circ} \mathrm{C}$, a uniform and denser Ag NP sintered layer was formed between the Ni/Ag plated Cu discs (Figure 5(e)). Since the more intense sintering happened at higher temperature, Ag NPs sintered and grew together causing the increase of material density and decrease of the porosity. As the sintering temperature reached $350^{\circ} \mathrm{C}$, much better metallurgical combination of joining zone was attained as shown in Figure 5(f). Some submicron voids still existed in the sintered layer but the porosity of the joint 


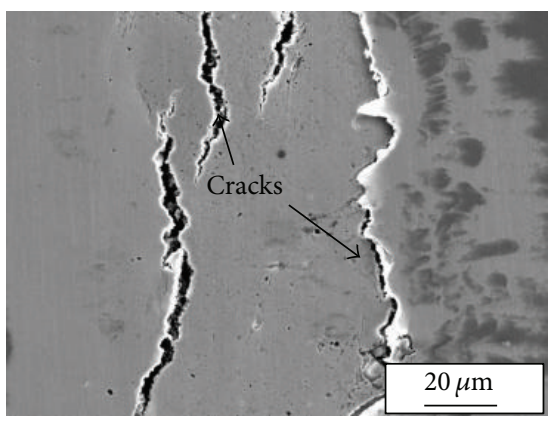

(a)

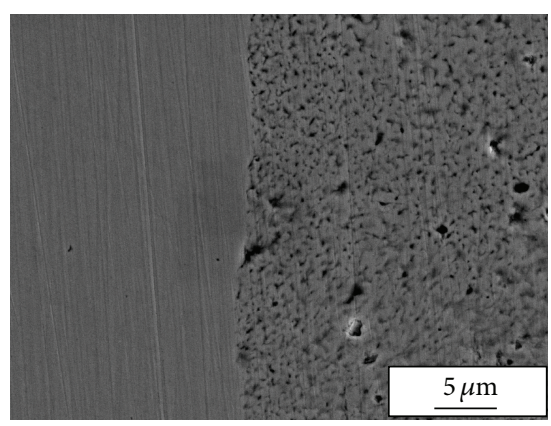

(d)

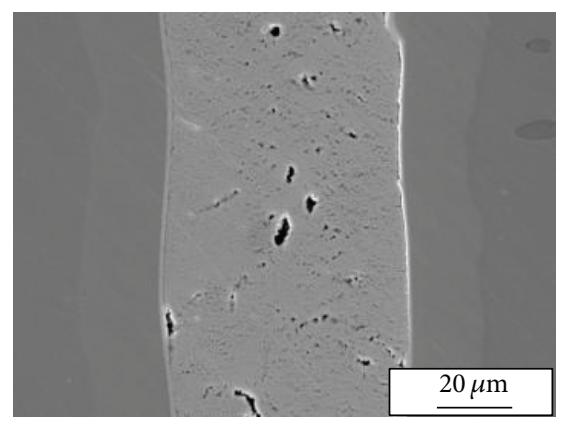

(b)

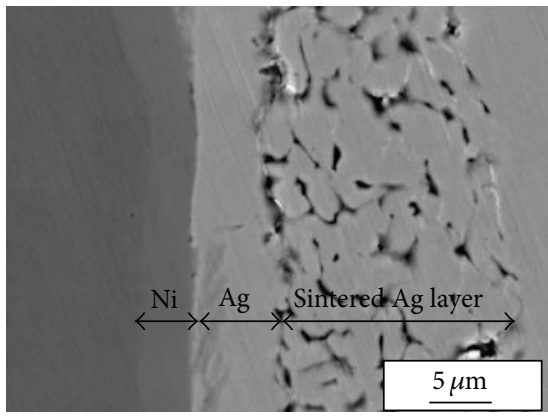

(e)

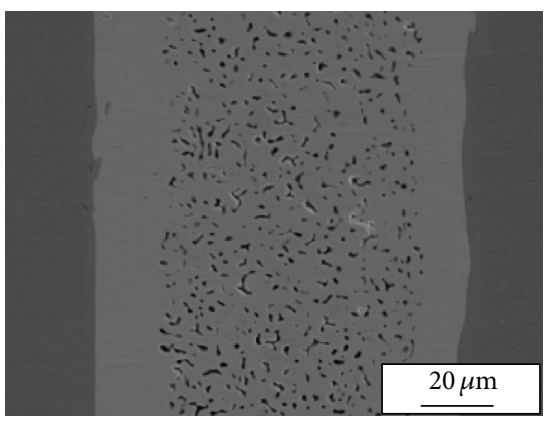

(c)

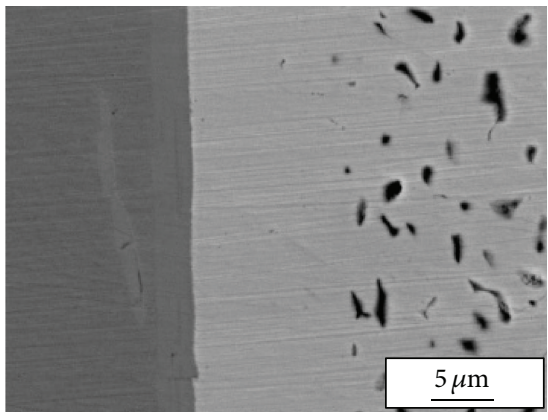

(f)

FIGURE 5: SEM images of interface microstructure of joints with different sintering temperatures: (a) low magnification at $150^{\circ} \mathrm{C}$; (b) low magnification at $250^{\circ} \mathrm{C}$; (c) low magnification at $350^{\circ} \mathrm{C}$; (d) high magnification at $150^{\circ} \mathrm{C}$; (e) high magnification at $250^{\circ} \mathrm{C}$; (f) high magnification at $350^{\circ} \mathrm{C}$.

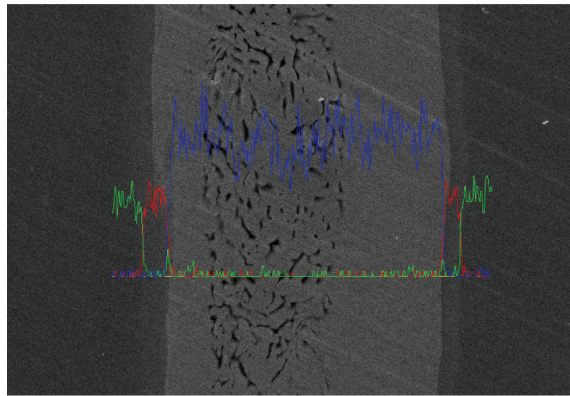

$40 \mu \mathrm{m}$

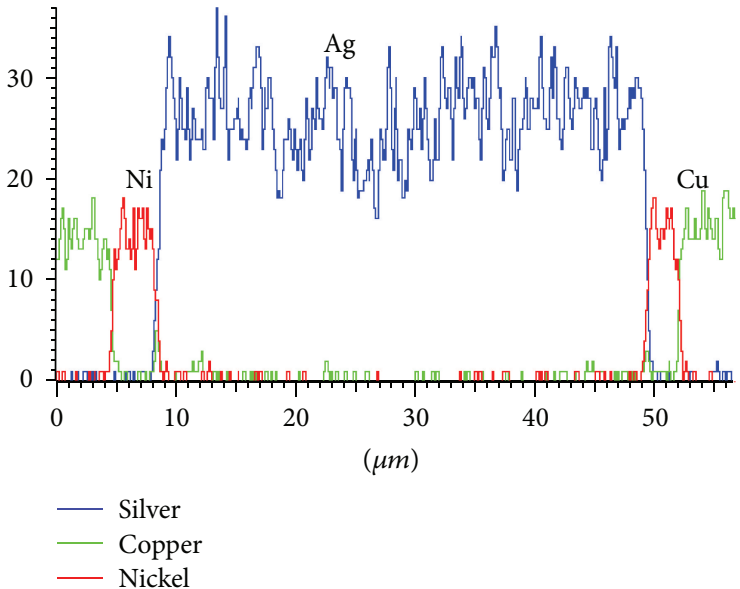

(b)

FIGURE 6: Microstructure of the joint: (a) line scan; (b) element distribution.

decreased compared with that at $250^{\circ} \mathrm{C}$. It is worth mentioning that the volume of the single pore increased with the sintering temperature from a few hundreds of nanometers to several microns. Benefiting from such porous structures, this sintered material could help relieve the thermomechanical stresses during operation. Moreover, the presence of such pores could balance the elastic modulus or other mechanical properties like strength and fatigue properties [31] of joints with the substrates, especially the plastic substrates. The chemical element distributions across the joining interface are shown in Figure 6. It can be seen that Ag content drops much sharply at the edge of Ni coating, and Ni coating does well on impeding Ag diffusion due to much lower solution of $\mathrm{Ag}$ in $\mathrm{Ni}$. No voids are discovered near the edge of $\mathrm{Ni}$ coating.

3.4. Mechanical Property of the Joints. Figure 7 shows the average shear strength of the sintered joints as a function of sintering temperature. The average strength of the joints at $150^{\circ} \mathrm{C}$ and $200^{\circ} \mathrm{C}$ was about $8 \mathrm{MPa}$ and $10 \mathrm{MPa}$, 


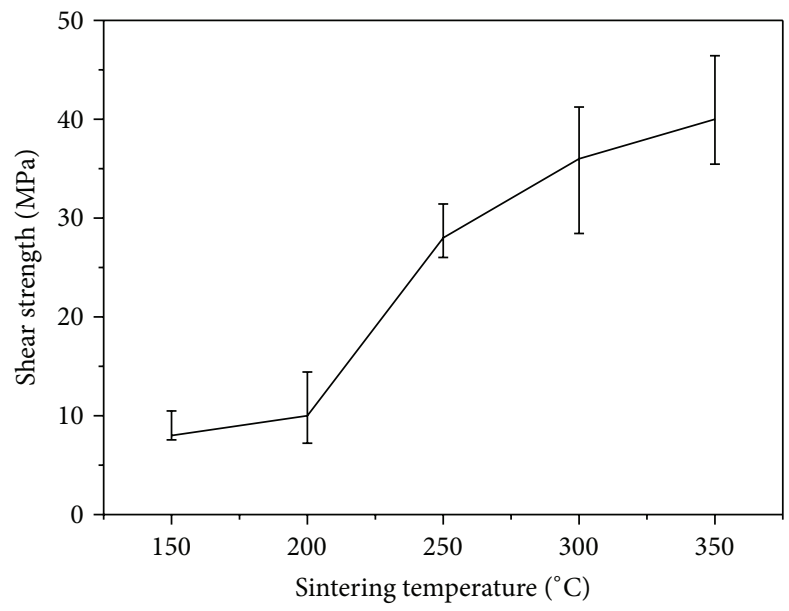

FIGURE 7: Average shear strength of sintered joints at different sintering temperatures.

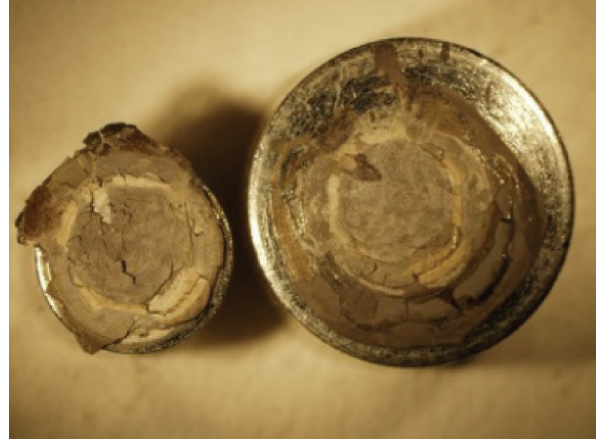

(a)

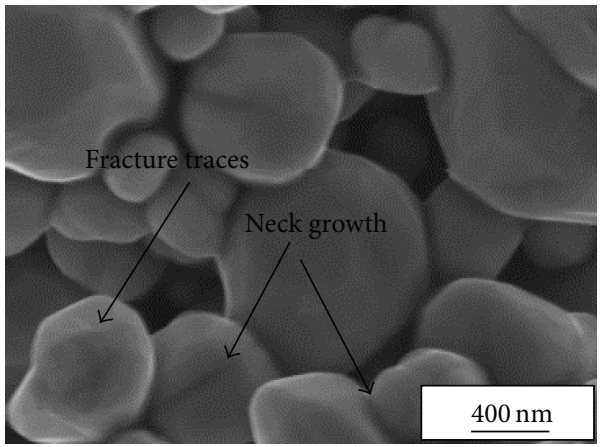

(c)

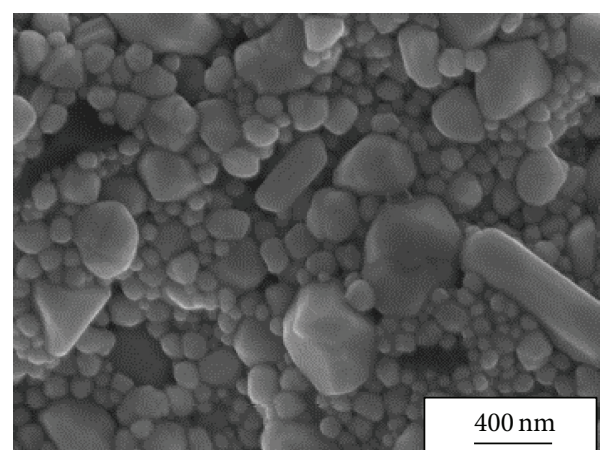

(b)

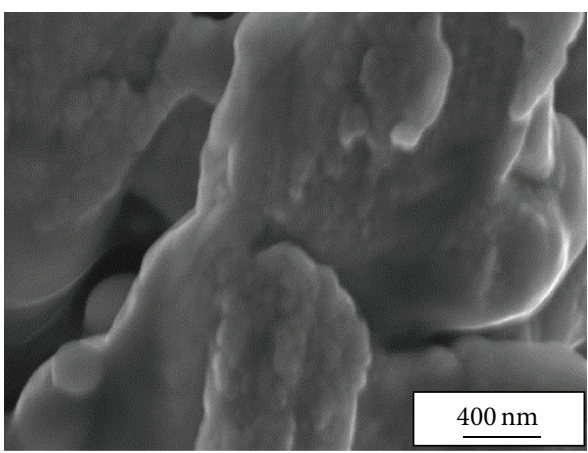

(d)

FIGURE 8: The fracture surface morphology of the joints. (a) Macromorphology. (b) Fracture at $150^{\circ} \mathrm{C}$. (c) Fracture at $250^{\circ} \mathrm{C}$. (d) Fracture at $350^{\circ} \mathrm{C}$.

respectively. When the sintering temperature increased to $250^{\circ} \mathrm{C}$, the average shear strength of the joint significantly increased to $28 \mathrm{MPa}$, which is comparable to the traditional lead solder and lead-free solder, suggesting that it could meet the requirements of electronic packaging $(24 \mathrm{MPa})$ in practical applications [13]. The average shear strength of $40 \mathrm{MPa}$ was achieved at sintering temperature of $350^{\circ} \mathrm{C}$. The higher temperatures are beneficial to the contact, diffusion, and sintering process between Ag NPs and substrate [32]. Therefore, higher sintering temperature could promote the sintering between Ag NPs and also between Ag NPs and substrates, which results in a better strength of joint.

Figure 8(a) shows the macrofracture surface of the joint. The ring-like structure on the fracture surface of the sintered joint as observed by Rautio et al. [33] due to the coffee ring effect caused by the rheological property of Ag NP paste was not obvious because of a very high content of Ag NPs in the paste. Figures $8(\mathrm{~b})-8(\mathrm{~d})$ show the fracture morphology of sintered Ag NPs joint at different temperatures from 150 to $350^{\circ} \mathrm{C}$. At low temperature of $150^{\circ} \mathrm{C}$ (Figure $8(\mathrm{~b})$ ), 
the majority of the Ag NPs were sintered together with clear the edges and corners, indicating that the Ag NPs maintained the original shape and sintering was feeble at low temperature. When the sintering temperature is $250^{\circ} \mathrm{C}$ (Figure 8(c)), obvious neck growth and particle growth were observed and sintering densification occurred. At $350^{\circ} \mathrm{C}$, the particle size grew further and large grain appeared resulting in a much denser sintering structure (see Figure $8(\mathrm{~d})$ ). The Ag NP size increased with the increase of the sintering temperature, as shown in Figures 8(b)-8(d). After measuring, it was found that $\mathrm{Ag}$ NPs on fracture surface sintered at $150^{\circ} \mathrm{C}, 250^{\circ} \mathrm{C}$, and $350^{\circ} \mathrm{C}$ were about $150 \mathrm{~nm}, 0.8 \mu \mathrm{m}$, and $1.2 \mu \mathrm{m}$, respectively. The phenomenon can be explained by the fact that the organic shell covered on Ag NPs decomposed faster and more completely at higher temperature [33]. The diffusion rate increased with the increasing of the sintering temperature, which resulted in the rapid coarsening of $\mathrm{Ag}$ NPs. Moreover, at high temperatures such as 250 to $350^{\circ} \mathrm{C}$ in this work, the Ag NPs became rounded and the corners were tuned (Figures 8(c) and 8(d)), which suggested that the liquid phase might appear during sintering. The liquid involved sintering would have much higher sintering speed than that of solid state sintering. It is worth mentioning that this liquid might only present on the surface of Ag NPs, the so-called surface melting [34], because the sintering temperatures are below the melting temperature of Ag NPs.

\section{Conclusions}

Ag NP paste with an average diameter of about $40 \mathrm{~nm}$ covered with organic shell 5-8 nm thick was synthesized via chemical reduction reaction. The organic shell can prevent the oxidation and aggregation of Ag NPs. TGA-DSC curves showed that the silver content was approximately 95.5 mass $\%$ in Ag NP paste and the organic shell vaporized, oxidized, or decomposed by reacting with the oxygen during the heating process in air. The sintered joint with Ag NP paste was successfully achieved at different temperatures with a rapid sintering process. With the increase of the sintering temperature, the interfacial microstructure of joint became denser. The average shear strength of the joint fabricated at $250^{\circ} \mathrm{C}$ for $5 \mathrm{~min}$ under $3 \mathrm{MPa}$ is $28 \mathrm{MPa}$ because of metallurgical bond formed between the silver plated layer and the sintered Ag NP layer, which could meet the requirements of electronics packaging. It suggests that this Ag NP paste as an alternative low-temperature connection material is suitable for high power semiconductor devices packaging with a rapid sintering process, which could also be applied to flexible electronic packaging.

\section{Conflict of Interests}

The authors declare that there is no conflict of interests regarding the publication of this paper.

\section{Acknowledgments}

This work was supported by International Science and Technology Cooperation Program of China (Grant no.
2013DFR50590) and the Fundamental Research Funds for the central University (30420100042, 3042012112, and 30420120771).

\section{References}

[1] R. R. Tummala, E. J. Rymaszewksi, and A. G. Klopfenstein, Microelectronics Packaging Handbook: Semiconductor Packaging, Part II, Chapman \& Hall, New York, NY, USA, 1997.

[2] H. K. Kim, H. K. Liou, and K. N. Tu, "Three-dimensional morphology of a very rough interface formed in the soldering reaction between eutectic SnPb and Cu," Applied Physics Letters, vol. 18, pp. 2337-2339, 1995.

[3] F. P. McCluskey, M. Dash, Z. Wang, and D. Huff, "Reliability of high temperature solder alternatives," Microelectronics Reliability, vol. 46, no. 9-11, pp. 1910-1914, 2006.

[4] I. E. Anderson, "Development of $\mathrm{Sn}-\mathrm{Ag}-\mathrm{Cu}$ and $\mathrm{Sn}-\mathrm{Ag}-\mathrm{Cu}-\mathrm{X}$ alloys for Pb-free electronic solder applications," in Lead-Free Electronic Solders, pp. 55-76, Springer, New York, NY, USA, 2007.

[5] K. J. Puttlitz and G. T. Galyon, "Impact of the ROHS directive on high-performance electronic systems," in Lead-Free Electronic Solders, pp. 347-365, Springer, New York, NY, USA, 2007.

[6] Y. Li, K.-S. Moon, and C. P. Wong, "Electronics without lead," Science, vol. 308, no. 5727, pp. 1419-1420, 2005.

[7] A. Katz, C. H. Lee, and K. L. Tai, "Advanced metallization schemes for bonding of InP-based laser devices to CVDdiamond heatsinks," Materials Chemistry and Physics, vol. 37, no. 4, pp. 303-328, 1994.

[8] A. J. Tessmer, L. S. Plano, and D. L. Dreifus, "High-temperature operation of polycrystalline diamond field-effect transistors," IEEE Electron Device Letters, vol. 14, no. 2, pp. 66-68, 1993.

[9] Y. Sugawara, "SiC devices for high voltage high power applications," Materials Science Forum, vol. 457-460, pp. 963-968, 2004.

[10] M. Zhang, M. Y. Efremov, F. Schiettekatte et al., "Size-dependent melting point depression of nanostructures: nanocalorimetric measurements," Physical Review B, vol. 62, no. 15, pp. 1054810557, 2000.

[11] Q. Jiang, S. H. Zhang, and J. C. Li, "Grain size-dependent diffusion activation energy in nanomaterials," Solid State Communications, vol. 130, no. 9, pp. 581-584, 2004.

[12] K. Katayama, H. Nomura, H. Ogata, and T. Eitoku, "Diffusion coefficients for nanoparticles under flow and stop-flow conditions," Physical Chemistry Chemical Physics, vol. 11, no. 44, pp. 10494-10499, 2009.

[13] E. Ide, S. Angata, A. Hirose, and K. F. Kobayashi, "Metal-metal bonding process using Ag metallo-organic nanoparticles," Acta Materialia, vol. 53, no. 8, pp. 2385-2393, 2005.

[14] J. R. Groza and A. Zavaliangos, "Nanostructured bulk solids by field activated sintering," Reviews on Advanced Materials Science, vol. 5, no. 1, pp. 24-33, 2003.

[15] M. Jakubowska, M. Jarosz, K. Kiełbasinski, and A. Młoniak, "New conductive thick-film paste based on silver nanopowder for high power and high temperature applications," Microelectronics Reliability, vol. 51, no. 7, pp. 1235-1240, 2011.

[16] J. G. Bai, Z. Z. Zhang, J. N. Calata, and G.-Q. Lu, "Lowtemperature sintered nanoscale silver as a novel semiconductor device-metallized substrate interconnect material," IEEE Transactions on Components and Packaging Technologies, vol. 29, no. 3, pp. 589-593, 2006. 
[17] J. Yan, G. Zou, X. Wang, H. Bai, F. Mu, and A. Wu, "Largescale synthesis of Ag nanoparticles by polyol process for low temperature bonding application," in Proceedings of the 12th International Conference on Electronic Packaging Technology and High Density Packaging (ICEPT-HDP '11), pp. 1-6, IEEE, Shanghai, China, August 2011.

[18] K. S. Moon, H. Dong, R. Maric et al., "Thermal behavior of silver nanoparticles for low-temperature interconnect applications," Journal of Electronic Materials, vol. 34, no. 2, pp. 168-175, 2005.

[19] J. Li, C. M. Johnson, C. Buttay, W. Sabbah, and S. Azzopardi, "Bonding strength of multiple $\mathrm{SiC}$ die attachment prepared by sintering of Ag nanoparticles," Journal of Materials Processing Technology, vol. 215, pp. 299-308, 2015.

[20] S. Wang, M. Y. Li, H. J. Ji, and C. Q. Wang, "Rapid pressureless low-temperature sintering of Ag nanoparticles for high-power density electronic packaging," Scripta Materialia, vol. 69, no. 1112, pp. 789-792, 2013.

[21] K. S. Siow, "Mechanical properties of nano-silver joints as die attach materials," Journal of Alloys and Compounds, vol. 514, pp. 6-19, 2012.

[22] W. S. Liao, T. Yang, E. T. Castellana, S. Kataoka, and P. S. Cremer, "A rapid prototyping approach to ag nanoparticle fabrication in the 10-100 nm range," Advanced Materials, vol. 18, no. 17, pp. 2240-2243, 2006.

[23] M. Yang, M. W. Chon, J. H. Kim et al., "Mechanical and environmental durability of roll-to-roll printed silver nanoparticle film using a rapid laser annealing process for flexible electronics," Microelectronics Reliability, vol. 54, no. 12, pp. 2871-2880, 2014.

[24] K. Kardarian, T. Busani, I. Osório et al., "Sintering of nanoscale silver coated textiles, a new approach to attain conductive fabrics for electromagnetic shielding," Materials Chemistry and Physics, vol. 147, no. 3, pp. 815-822, 2014.

[25] M. Layani, M. Grouchko, S. Shemesh, and S. Magdassi, "Conductive patterns on plastic substrates by sequential inkjet printing of silver nanoparticles and electrolyte sintering solutions," Journal of Materials Chemistry, vol. 22, no. 29, pp. 14349-14352, 2012.

[26] H. Yu, L. L. Li, and Y. J. Zhang, "Silver nanoparticle-based thermal interface materials with ultra-low thermal resistance for power electronics applications," Scripta Materialia, vol. 66, no. 11, pp. 931-934, 2012.

[27] Y. Sun and Y. Xia, "Shape-controlled synthesis of gold and silver nanoparticles," Science, vol. 298, no. 5601, pp. 2176-2179, 2002.

[28] S. Li, P. Liu, and Q. Wang, "Study on the effect of surface modifier on self-aggregation behavior of Ag nano-particle," Applied Surface Science, vol. 263, pp. 613-618, 2012.

[29] L. Mo, D. Liu, W. Li, L. Li, L. Wang, and X. Zhou, "Effects of dodecylamine and dodecanethiol on the conductive properties of nano-Ag films," Applied Surface Science, vol. 257, no. 13, pp. 5746-5753, 2011.

[30] D. L. Chen, M. N. Liu, Q. Q. Chen et al., "Large-scale synthesis and enhanced visible-light-driven photocatalytic performance of hierarchical $\mathrm{Ag} / \mathrm{AgCl}$ nanocrystals derived from freeze-dried PVP- $\mathrm{Ag}^{+}$hybrid precursors with porosity," Applied Catalysis B: Environmental, vol. 144, pp. 394-407, 2014.

[31] J. Li, Thermo-Mechanical Reliability of Sintered Silver Joint Versus Lead-Free Solder for Attaching Large Area Device, Virginia Polytechnic Institute and State University (Materials Science and Engineering), Blacksburg, Va, USA, 2010.

[32] G. S. Zou, J. F. Yan, F. W. Mu, A. Wu, J. Ren, and A. Hu, "Low temperature bonding of $\mathrm{Cu}$ metal through sintering of $\mathrm{Ag}$ nanoparticles for high temperature electronic application," The Open Surface Science Journal, vol. 3, no. 1, pp. 70-75, 2011.

[33] J. Rautio, P. Perämäki, J. Honkamo, and H. Jantunen, "Effect of synthesis method variables on particle size in the preparation of homogeneous doped nano $\mathrm{ZnO}$ material," Microchemical Journal, vol. 91, no. 2, pp. 272-276, 2009.

[34] H. A. Alarifi, M. Atiş, C. Özdoğan, A. Hu, M. Yavuz, and Y. Zhou, "Determination of complete melting and surface premelting points of silver nanoparticles by molecular dynamics simulation," The Journal of Physical Chemistry C, vol. 117, no. 23, pp. 12289-12298, 2013. 

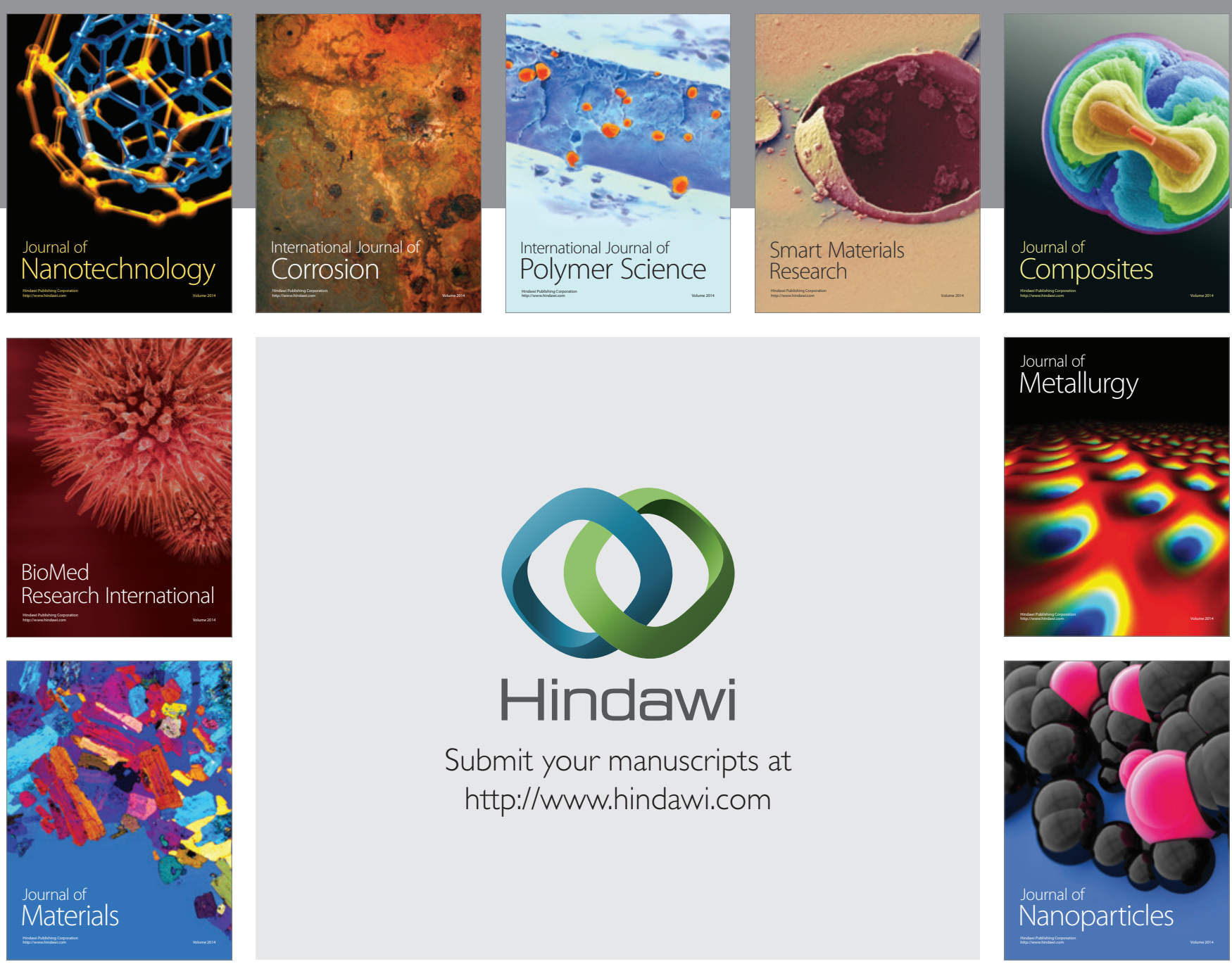

Submit your manuscripts at http://www.hindawi.com
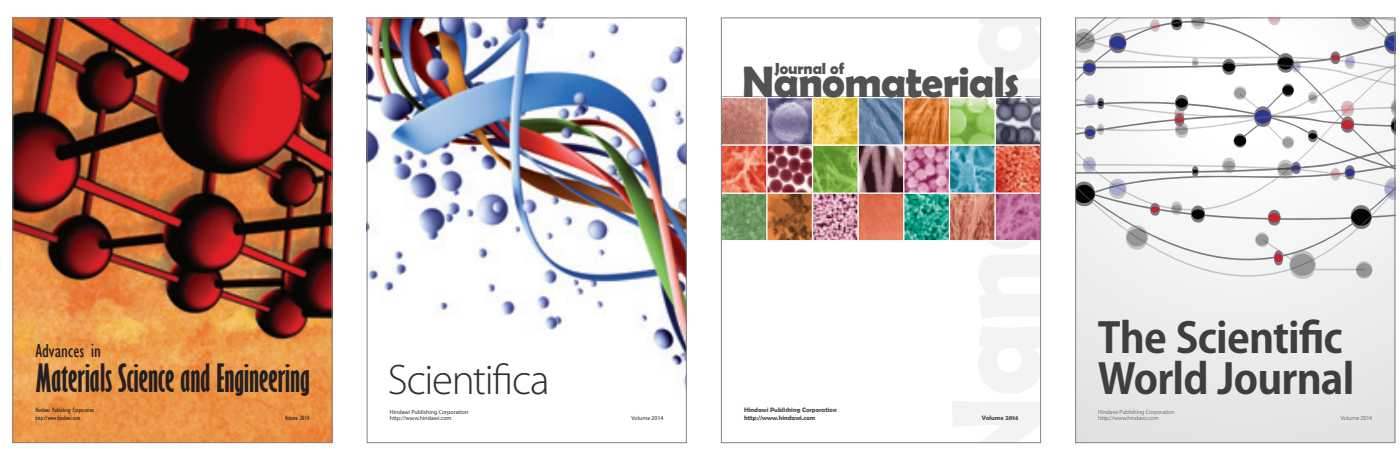

\section{The Scientific World Journal}
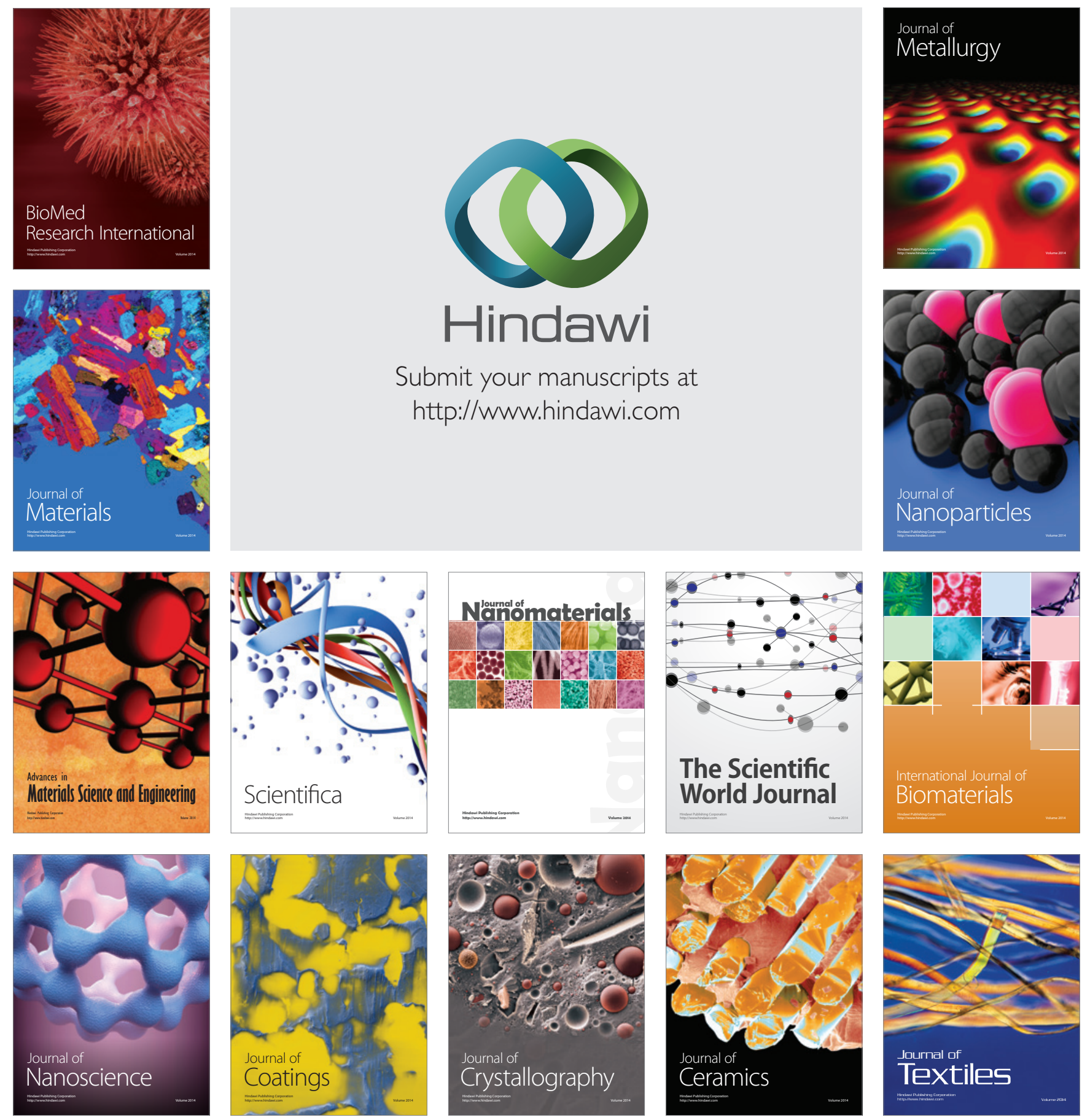